\title{
EFFECT OF ERECTOR SPINAE PLANE BLOCK FOR RIB FRACTURES ON POSTOPERATIVE ANALGESIA FOR ELBOW SURGERY: A CASE REPORT
}

\author{
Bhattarai $P R^{1^{*}}$, Sharma $A^{2}$, Khadka $R^{3}$, Sharma $A^{4}$
}

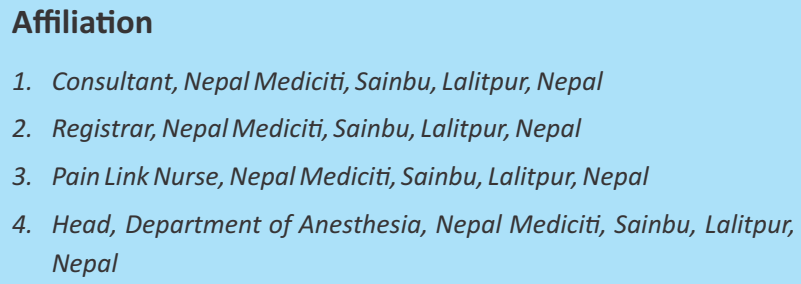

1. Consultant, Nepal Mediciti, Sainbu, Lalitpur, Nepal

2. Registrar, Nepal Mediciti, Sainbu, Lalitpur, Nepal

3. Pain Link Nurse, Nepal Mediciti, Sainbu, Lalitpur, Nepal

4. Head, Department of Anesthesia, Nepal Mediciti, Sainbu, Lalitpur, Nepal

\section{ARTICLE INFO}

$\begin{array}{ll}\text { Received } & : 9 \text { August, } 2020 \\ \text { Accepted } & : 21 \text { November, } 2020 \\ \text { Published } & : 22 \text { December, } 2020\end{array}$

C) Authors retain copyright and grant the journal right of first publication with the work simultaneously licensed under Creative Commons Attribution License CC - BY 4.0 that allows others to share the work with an acknowledgment of the work's authorship and initial publication in this journal.

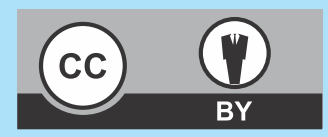

CR 36

DOI: https://doi.org/10.3126/bjhs.v5i3.33716

* Corresponding Author
Dr. Prajjwal Raj Bhattarai
Consultant
Nepal Mediciti, Sainbu, Lalitpur, Nepal
Email: prajjwal.bhattarai@gmail.com
ORCID ID: https://orcid.org/0000-0001-6895-6920

\section{Citation}

Bhattarai PR, Sharma A, Khadka R, Sharma A. Effect of Erector Spinae Plane Block for Rib Fractures on Postoperative Analgesia for Elbow Surgery: A Case Report. BJHS 2020;5(3)13.1255-1257.

\section{ABSTRACT}

The erector spinae plane block is an emerging technique for analgesia. It has shown to provide reliable analgesia in abdominal and thoracic surgery. Erector spinae plane block may be efficacious for analgesia of pain in the upper limb. The advantage of this modality would be in a patient with polytrauma with rib fractures and upper limb fracture/ injury as it assists in the physiotherapy of the chest and upper limb.

\section{KEYWORDS}

ESP block, Rib fractures, multiple trauma, elbow surgery, regional anesthesia 


\section{INTRODUCTION}

Erector spinae plane (ESP) block is emerging as a novel technique of analgesia in case of abdominal surgery ${ }^{1}$, thoracic surgery ${ }^{2}$ and in case of rib fractures. ${ }^{3}$

We report a case where the analgesic effects of the thoracic ESP block extended beyond the expected boundaries.

\section{CASE REPORT}

A 29-year-old male patient with a history of a road traffic accident was brought to our hospital. On evaluation, he had fracture of $4^{\text {th }}$ to $7^{\text {th }}$ ribs on the left side along with a pneumohemothorax on the same side for which thoracostomy tube drainage was inserted in emergency roomand there was fracture of the olecranon process of the left elbow. The vital signs were stable on presentation. However, he complained of pain (NRS=10/10) on the left side of the chest and that he could not lie flat. He is a professional sportsman and was posted for fixation of an olecranon fracture on the same day. Review of other systems including laboratory test was within normal limits. An erector spinae plane catheter was planned for the management of pain for the rib fractures and a brachial plexus block was planned for open reduction and internal fixation (ORIF) of the fractured olecranon process. Preanesthetic evaluation was done and written informed consent was taken. The patient was shifted to the preoperative room where ultrasound-guided (linear SIEMENS $\left({ }^{\mathrm{TM}}\right)$ ) ESP catheter was inserted at the T2-T3 level with $18 \mathrm{G}$ Tuohy needle and a $20 \mathrm{G}$ catheter threaded through the needle. Twenty $\mathrm{ml}$ of $0.5 \%$ ropivacaine was injected via the catheter. (Fig 1) After 20 minutes the pain in the chest was $3 / 10$ and the patient was shifted to the operating room. Under aseptic precautions, 1.5\% lidocaine with adrenaline $20 \mathrm{ml}$ was injected to block the left brachial plexus via the supraclavicular approach under ultrasound guidance. Dexmedetomidine was started to maintain sedation at Richmond Agitation and Sedation Score (RASS) 1 to -2 , throughout the surgery. Surgery was uneventful. In the postoperative period, intermittent boluses of $0.2 \%$ ropivacaine $20 \mathrm{ml}$ four-hourly via ESP catheter was administered. Additional boluses of $20 \mathrm{ml}$ of $0.2 \%$ ropivacaine were administered if NRS was 4 or more with the lockout interval set at 45 minutes. Additionally, injection paracetamol 1 gram IV 8 hourly was prescribed as part of multimodal analgesia and injection pethidine $25 \mathrm{mg}$ IV was prescribed as rescue analgesia, if required. Onpostoperative day 1 and day 2, NRS was 1 to 2 at all times, and the patient did not require rescue analgesia. On day 2 , we noticed that the patient did not have pain at the surgical site, the left elbow, during cast removal and passive mobilization. The chest tube was removed on the same day. The same regimen for analgesia was continued through postoperative day 3 and 4 . On postoperative day 5 , ropivacaine was temporarily stopped to reassess the requirement of further boluses. As the patient was free of pain, the ESP catheter was removed on day 6 and the patient was discharged home

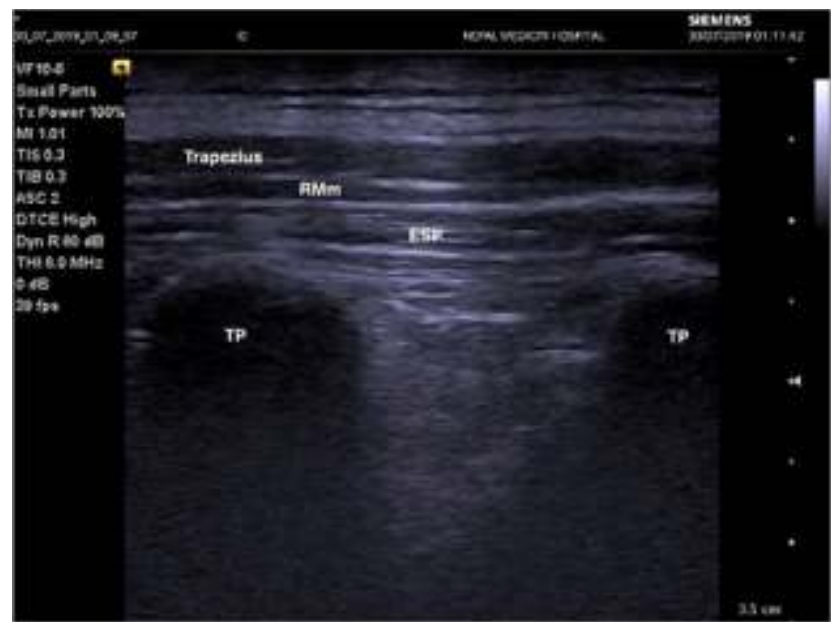

Figure 1: Ultrasound image. (TP: Transverse Process; RMm: Rhomboid Major Muscle; ESP: Erector Spinae Plane)

\section{DISCUSSION}

Even without opioid analgesics, we observed the patient to be pain free postoperatively. We believe that the ESP block placed to provide analgesia for pain due to rib fractures provided the additional advantage of analgesia for elbow surgery. A brief review of the anatomy of the erector spinae plane likely helps understand this effect.

Erector spinae muscle is a group of three muscles i.e. iliocostalis which originates from the sacrum and iliac crest, longissimus from the sacrum and transverse process of T1T6, and spinalis from the spinous process of C6-L3. The iliocostalis insert in the 6th rib to 12 rib and posterior tubercle of the transverse process of $\mathrm{C} 3$ to $\mathrm{C} 6$, longissimus inserts into the transverse processes of C2- L5 and the mastoid process of the occipital bone and spinalis inserts into the spinous process of $\mathrm{C} 2-\mathrm{C} 8$ and external occipital protuberance. As ESP extends to the muscle plane in the lumbar area, it can also provide effective analgesia during upper abdominal surgeries. Moreover, the extension of this plane in the cervical level allows the spread of drug to the cervical foramina and nerve roots resulting in analgesia in the shoulder region. Furthermore, as only a small volume of local anaesthetic reaches the cervical region, sensory fibers are blocked first effectively sparing the motor fibers.4This is because, at small concentrations, anesthetics with higher pKa (like bupivacaine and ropivacaine) consistently block smaller nociceptive $C$ fibers ahead of larger myelinated motor A fibers. ${ }^{5}$ We believe this effect benefited this patient by assisting with early physiotherapy and recovery.

Forero $\mathrm{M}$ et al described ESP block in 2016 for neuropathic, post-surgical pain and post-traumatic pain in thorax. (6) Since then, this has been recognized as a simple, safe and efficient ultrasound-guided technique in regional anesthesia. The local anesthetic is injected below the erector spinae muscle through the catheter so that the drug spreads in both cranial and caudal directions to multiple vertebral spaces. The exact mechanism how the block works are not very well understood, yet it is suggested that the anesthetic injected from the ESP plane spreads to 
paravertebral space and intercostal space, thus acting on dorsal and ventral spinal rami. ${ }^{4}$ Hence, it had been claimed to be a reliable analgesic modality for the management of ribs fracture, post-thoracotomy pain for lung or heart surgeries.

As a point of support to our observation, the ESP catheter kept at T2-T3 level has been used for the management of shoulder pain in several reported cases. Forero et al. demonstrated the spread of radiocontrastup to as high as C3 via computed tomography. ${ }^{4}$ As the dermatomal distribution at shoulder joint is $\mathrm{C} 4-\mathrm{C} 5$, analgesia that effectively blocks the shoulder pain likely blocks the pain at the elbow as it is supplied by T1 dermatome medially and C5-C6 dermatomes laterally.

\section{CONCLUSION}

A conclusion that can be drawn from our case is that the analgesic effect may be attributed due to the spread of the drug to the cervical region with resulting the blockade of the cervical nerve roots. However, we are cautious against undue generalizations as we believe the successful management of a single case is not enough to suggest any conclusions. But we reckon that this finding should provide an impetus towards using the ESP block for management of post-traumatic pain and assisting with upper limb physiotherapy in the same.

\section{PATIENT CONSENT}

None

\section{CONFLIT OF INTEREST}

None

\section{REFERENCES}

1. Luuis-Navarro J, Seda-Guzmán M, Luis-Moreno C, Chin K-J. Erector spinae plane block in abdominal surgery: Case series. Indian J Anaesth. 2018;62(7):549. doi: 10.4103/ija.IJA_57_18

2. Ince I, Ozmen O, Aksoy M, Zeren S, Ulas AB, Aydin Y. Erector Spinae Plane Block Catheter Insertion under Ultrasound Guidance for Thoracic Surgery: Case Series of Three Patients. Eurasian J Med 2018; 50(3): 204-206.doi: 10.5152/eurasianjmed.2018.18147

3. Hamilton DL, Manickam B. Erector spinae plane block for pain relief in rib fractures. Br J Anaesth. 2017;118(3):474-475. doi:10.1093/ bja/aex013
4. Forero M, Rajarathinam M, Adhikary SD, Chin KJ. Erector spinae plane block for the management of chronic shoulder pain: a case report. Can J Anaesth. 2018 Mar;65(3):288-293. doi: 10.1007/ s12630-017-1010-1.

5. Douglas J. Ford, P. Prithvi Raj, Pritam Singh, Karen M. Regan, David Ohiweiler; Differential Peripheral Nerve Block by Local Anesthetics in the Cat. Anesthesiology 1984;60(1):28-33.

6. Forero M, Adhikary SD, Lopez H, Tsui C, Chin KJ. The Erector Spinae Plane Block: A Novel Analgesic Technique in Thoracic Neuropathic Pain. Reg Anesth Pain Med. 2016;41(5):621-627. doi:10.1097/ AAP. 0000000000000451 